\title{
The Influence of Gas Atmosphere Composition on Formation of Surface Films in Self-Propagating High-Temperature Synthesis of Porous $\mathrm{Ti}_{3} \mathrm{SiC}_{2}$
}

\author{
Aleksandr Petrovich Amosov ${ }^{1,2}$, Evgeniy Ivanovich Latukhin ${ }^{1,2} \&$ Denis Mikhaylovich Davydov ${ }^{2}$ \\ ${ }^{1}$ Samara State Aerospace University, Samara, Russia \\ ${ }^{2}$ Samara State Technical University, Samara, Russia \\ Correspondence: Aleksandr Petrovich Amosov, Samara State Aerospace University, Samara, Russia. Tel: \\ 7-846-267-4640. E-mail: egundor@yandex.ru
}

Received: October 19, 2014

Accepted: October 29, $2014 \quad$ Online Published: December 10, 2014

doi:10.5539/mas.v9n3p17

URL: http://dx.doi.org/10.5539/mas.v9n3p17

\begin{abstract}
In the present work, the structure and composition of the surface layer formed during self-propagating high-temperature synthesis (SHS) of porous ternary carbide $\mathrm{Ti}_{3} \mathrm{SiC}_{2}$ from the initial mixture of powders $3 \mathrm{Ti}+1.15 \mathrm{Si}+2 \mathrm{C}$ in the surrounding gas atmosphere of different compositions were investigated. Using X-ray analysis, scanning electron microscopy and energy dispersive analysis, it was shown that a porous composite material, consisting of the main phases $\mathrm{Ti}_{3} \mathrm{SiC}_{2}$ and $\mathrm{TiC}$, is synthesized under these conditions. During the synthesis in atmospheres of air and nitrogen, a film of 2-3 microns thickness consisting of $\mathrm{TiO}_{2}$ and $\mathrm{TiN}$ is formed on the surface of the porous material. During the SHS process in an inert argon atmosphere and in vacuum, this film is not formed. In nitrogen atmosphere, conglomerates of TiN particles are formed on the film as well.
\end{abstract}

Keywords: porous ceramics, $\mathrm{Ti}_{3} \mathrm{SiC}_{2}$, self-propagating high-temperature synthesis, surface film, $\mathrm{TiO}_{2}, \mathrm{TiN}$

\section{Introduction}

The development of porous ceramic materials have received much attention because they are widely used as filters for liquids and gases, bulk carriers of catalysts, bioimplants (Liu \& Chen, 2014; Vityaz, et al., 2010; Ilyushenko, et al., 2010). In contrast to the polymer and metal porous materials, they have high temperature resistance, corrosion resistance, and biocompatibility. This allows them to be applied, for example, at high temperatures of filtering molten metals, filtering and catalytic afterburning of exhaust gases from diesel and gasoline engines (Emmela, et al., 2014; Kašpar, et al., 2003; Adler, 2005). The main disadvantages of conventional porous ceramics on the basis of the most common binary refractory compounds (oxides, carbides, borides, etc.) are its brittleness and low resistance to mechanical and thermal shocks.

Recently in materials science, great attention is paid to a new type of refractory compounds - MAX-phases (Barsoum, 2000; Hu, 2013). MAX-phases refer to the ternary compounds corresponding to the formula $M_{n+1} A X_{n}$ with hexagonal dense packing, where $\mathrm{M}$ is a transition metal, $\mathrm{A}$ is an element of $\mathrm{A}$ subgroup of the periodic system of elements, $\mathrm{X}$ is carbon or nitrogen. The best properties of metals and ceramics are combined in the MAX-phases. As metals, they are electrical and thermal conducting, are easily processed by cutting at room temperature, resist the propagation of cracks, are not sensitive to thermal shock, are ductile at high temperatures. As ceramics, they have low density, have high values of characteristics of elasticity, are characterized by high thermal stability and heat resistance. The MAX-phases can become the basis of new porous ceramic materials, reasonably tough and resistant to mechanical and thermal shocks, and bring the application of porous ceramic materials to a new level.

One of the first MAX-phase was titanium silicon carbide $\left(\mathrm{Ti}_{3} \mathrm{SiC}_{2}\right)$ synthesized in 1967 (Jeitschko \& Nowotny, 1967). But its unique properties have been identified and explained much later, when it was found that the structure of $\mathrm{Ti}_{3} \mathrm{SiC}_{2}$ is an alternation of nanoscale plates of titanium carbide (TiC) bonded by atomic layers of silicon ( $\mathrm{Si}$ ) (Barsoum, 2000). $\mathrm{Ti}_{3} \mathrm{SiC}_{2}$ has, for example, ultra-low coefficient of friction, which predetermined the perspective of its use as a tribological material (Myhra, et al., 1999). To increase the rigidity and strength of reasonably soft $\mathrm{Ti}_{3} \mathrm{SiC}_{2}$, a variety of composite materials based on it with high thermal and corrosion resistance, 
and biocompatibility is developed (Ren, et al., 2010; Hu, et al., 2014; Ngai, et al., 2014). Along with dense, pore-free materials, $\mathrm{Ti}_{3} \mathrm{SiC}_{2}$ porous materials are considered, promising both for the above traditional applications of the porous materials and for other applications, for example, such as mechanical dampers (Fraczkiewicz, et al., 2006).

Porous $\mathrm{Ti}_{3} \mathrm{SiC}_{2}$ can be obtained by a variety of ways, which can be divided into two groups. The first group includes methods of reaction sintering of a mixture of powders of starting components with external high-temperature heating and with the application of pressure or without the application of pressure (Fraczkiewicz, et al., 2006; Li, et al., 2004; Sun, et al., 2005; Zhou, et al., 2014). The second group consists of methods of self-propagating high-temperature synthesis (SHS) by burning a mixture of powders, when high temperatures are reached not due to external electrical heating, but due to the internal heat of combustion (Pampuch, et al., 1989; Liang, et al., 2009; Meng, et al., 2013). In the first group, an expensive energy-intensive equipment is used, whereas in the second group it is a simple equipment with low energy consumption, so SHS methods are seen as more economical for the organization of industrial production of $\mathrm{Ti}_{3} \mathrm{SiC}_{2}$ materials and from this point of view, they are relevant for further improvement (Liang, et al., 2009; Meng, et al., 2013).

One of the areas of improvement, which is the focus of much research is the increase of the target phase $\mathrm{Ti}_{3} \mathrm{SiC}_{2}$ in the product synthesized, which usually along with this phase contains the impurity phases, first of all, the titanium carbide (TiC). Another area of improvement could be the formation of functional coatings on the surface of the porous $\mathrm{Ti}_{3} \mathrm{SiC}_{2}$, and here we can mention only one study (Liang, et al., 2009), in which the formation of an oxide layer of $\mathrm{TiO}_{2}$ on the surface of the porous $\mathrm{Ti}_{3} \mathrm{SiC}_{2}$ was observed when it was obtained from mechanically activated mixture of powders $3 \mathrm{Ti}+\mathrm{Si}+2 \mathrm{C}$ through the performance of SHS process in the air. It is known that the functional coating can significantly improve the performance characteristics of porous materials: physical, mechanical, corrosive, catalytic, biocompatible (Vityaz, et al., 2010; Ilyushenko, et al., 2010; Smorygo, et al., 2008; Browne \& Gregson, 1994; Sul \& Johansson, 2005). For example, coatings of TiN and $\mathrm{TiO}_{2}$ on implants significantly improve the osseointegration of bone tissue with orthopedic implants and hemocompatibility of cardiac implants with blood components (Ilyushenko, et al., 2010; Browne \& Gregson, 1994; Sul \& Johansson, 2005).

The aim of this work is to study the influence of the composition of the gas atmosphere on the formation of surface layers with self-propagating high-temperature synthesis of porous $\mathrm{Ti}_{3} \mathrm{SiC}_{2}$ from a mixture of powders of Ti-Si-C.

\section{Materials and Methods}

For the experiment, the following powders was used: titanium of grade PTM-2 with a purity of $98.9 \%$ and a particle size of 6-15 microns, silicon of grade KR0 with a purity of $98.8 \%$ and a particle size of $1-15$ microns, soot of grade P-800 with a particle size of 0.09-0.13 micron. When choosing the composition of the starting powder mixture, it was taken into account that the increase in silicon content of $15 \%$ with respect to stoichiometry leads to the maximum quantity of MAX-phase in the reaction products (Meng, et al., 2013). In the present work, the problem of optimizing the composition of the products of synthesis on the content of the MAX-phase was not considered, therefore, the composition of the initial mixture of powders was held constant. The initial mixture in the ratio $3 \mathrm{Ti}+1.15 \mathrm{Si}+2 \mathrm{C}$ was mixed in a ball mill. Cylindrical preforms with a diameter of $23 \mathrm{~mm}$, weight of $10 \mathrm{~g}$ with a relative density of about 0.5 were made from the powder mixture by unilateral pressing at a pressure of $5.5 \mathrm{MPa}$.

The reaction of self-propagating high-temperature synthesis of $\mathrm{Ti}_{3} \mathrm{SiC}_{2}$ was initiated through the ignition of the end of the preform with an electric coil in a laboratory SHS reactor of 4.5 litres described in (Shiganova, et al., 2011), or outdoors on fireclay brick, or in the filling of sand according to the scheme presented in Figure 1. 


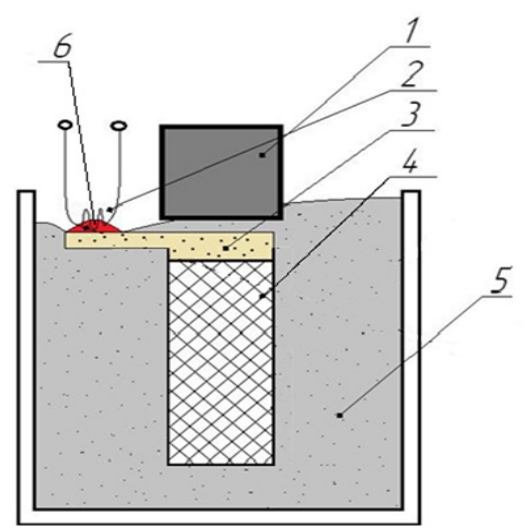

Figure 1. Scheme of SHS in the sand filling. 1 - weight, 2 - nichrome spiral, 3 - incendiary mixture, 4 - preform of Ti-Si-C, 5 - sand filler, 6 - thermite mixture

Filling of sand prevented the burning preform from immediate contact with atmospheric air, at the same time allowing the gases released during the burning of the preform to infiltrate through the filling into the surrounding air. While a weight of $0.2 \mathrm{~kg}$ did not allow the emitted gases to throw sand from the end of the preform and to provide the immediate contact with air. Glowing nichrome spiral lit first magnesium termite $4 \mathrm{Mg}+\mathrm{Fe}_{3} \mathrm{O}_{4}$, then the burning went on incendiary mixture consisting of the same composition as the preform, but in non-compacted form, which lit the preform end.

To study the influence of the composition of the gas atmosphere on the formation of surface films, samples of $\mathrm{Ti}_{3} \mathrm{SiC}_{2}$ were synthesized in SHS reactor in vacuum $(0,01 \mathrm{MPa})$ or in atmospheres of nitrogen (1 MPa) or argon $(0.1$ and $4 \mathrm{MPa})$. Air atmosphere was used during the combustion of the preforms in the open air and in the sand filling.

The obtained samples were investigated by scanning electron microscope JEOL-6390A with attachment of energy dispersive analyzer (EDS) Jeol JED-2200. Phase composition was determined by X-ray method using a diffractometer ARL'XtrA.

\section{Results}

The surface morphology of the pore space of $\mathrm{Ti}_{3} \mathrm{SiC}_{2}$ samples synthesized in air and in sand filling were investigated using scanning electron microscope and presented respectively in Figures 2 and 3. It is seen that the surface of the open pores is covered with a layer of film with thickness of 2-3 microns, and in both cases, as in the synthesis of the material in the open air, and in the sand filling, the surface film is formed of the same thickness and morphology. In addition, typical plates of titanium silicon carbide and grains of titanium carbide are visible under the surface film in the structure of the porous frame.

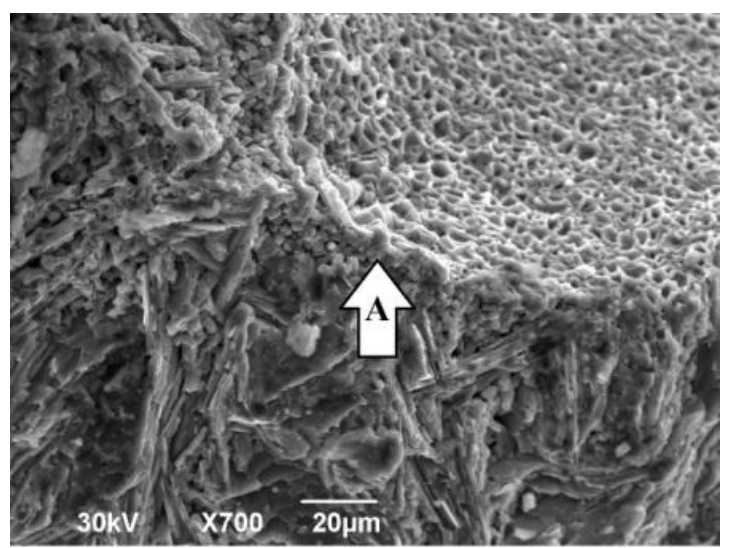

Figure 2. Microstructure of the surface of $\mathrm{Ti}_{3} \mathrm{SiC}_{2}$, synthesized in air. A - surface film 


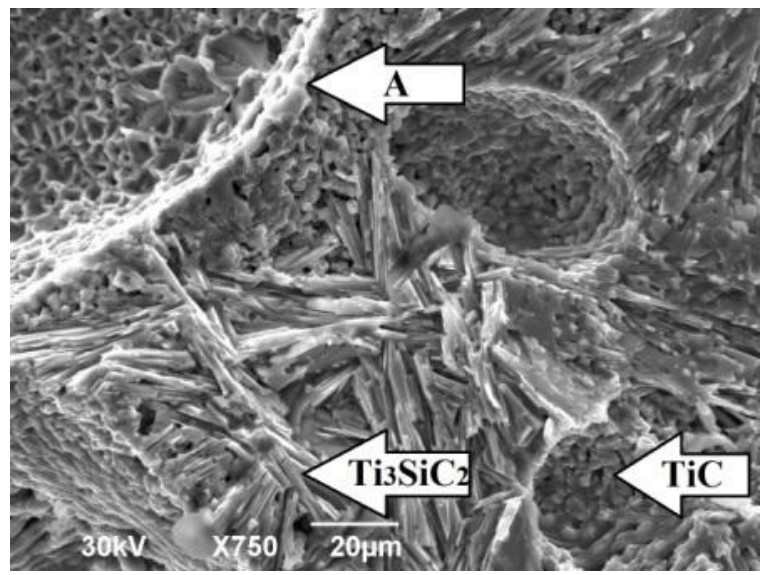

Figure 3. Microstructure of the surface of $\mathrm{Ti}_{3} \mathrm{SiC}_{2}$, synthesized in sand. A - surface film

The surface morphology of the pore space of $\mathrm{Ti}_{3} \mathrm{SiC}_{2}$ samples synthesized in nitrogen atmosphere is shown in Figure 4. Here conglomerates of particles A appeared on the surface of the film B. The elemental composition of the film and conglomerates on its surface were analyzed using energy dispersive analyzer EDS. The results of the analysis of the chemical composition of the surface films are shown in Table 1.

We can conclude from the Table 1 that the surface films must contain oxides and nitrides primarily of Ti.

According to results of energy dispersive analysis (they are not presented here), the particles included in the conglomerates contain large quantities of titanium and nitrogen, that is, they are particles of titanium nitride (TiN).

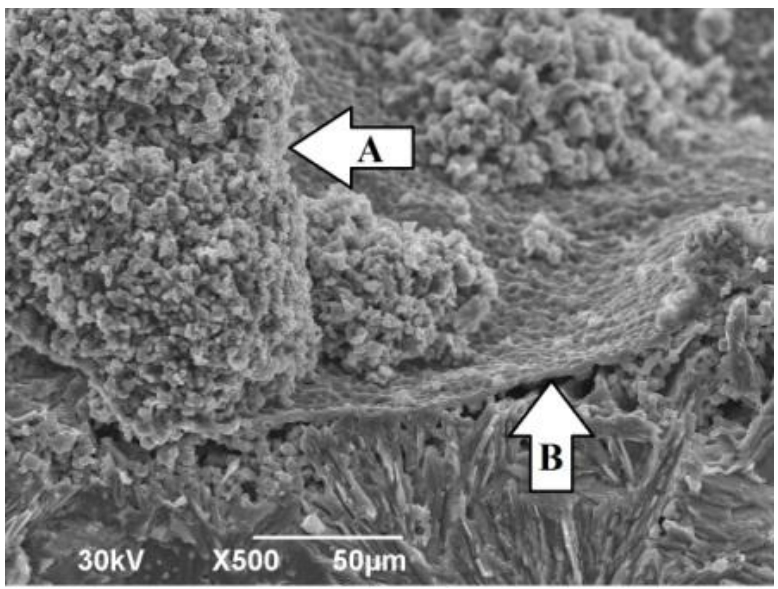

Figure 4. Microstructure of the surface of $\mathrm{Ti}_{3} \mathrm{SiC}_{2}$, synthesized in nitrogen atmosphere.

A - conglomerates of particles on the film surface; B - surface film.

Table 1. Element content (wt. \%) in surface films on $\mathrm{Ti}_{3} \mathrm{SiC}_{2}$ samples synthesized in different atmospheres

\begin{tabular}{llllll}
\hline Atmosphere & $\mathrm{Ti}$ & $\mathrm{Si}$ & $\mathrm{C}$ & $\mathrm{O}$ & $\mathrm{N}$ \\
\hline Open air & 78.2 & 5.9 & 4.3 & 5.6 & 6.0 \\
Sand filling & 80.9 & 5.2 & 3.8 & 4.3 & 5.8 \\
Nitrogen & 77.1 & 6.8 & 4.1 & 1.2 & 10.8 \\
\hline
\end{tabular}

The following batches of samples were synthesized in the inert atmosphere of argon and in vacuum to eliminate the influence of air on the surface processes during the synthesis. The pressure of argon in the synthesis was 0.1 and $4 \mathrm{MPa}$, the pressure at the vacuum was $0,01 \mathrm{MPa}$.

The results showed that in the atmosphere of inert gas and in vacuum, there is no film or conglomerates of 
particles on the surface of the pore space. It can be seen from Figures 5 and 6 , which present the surface morphology of the pores of the samples synthesized in the SHS mode, respectively, in the argon atmosphere and in vacuum, without any films and growths. Grains of $\mathrm{TiC}$ surrounded by plates $\mathrm{of} \mathrm{Ti}_{3} \mathrm{SiC}_{2}$ are visible on the fracture only.

$\mathrm{X}$-ray phase analysis was performed for all samples. A typical X-ray diffraction pattern of the porous $\mathrm{Ti}_{3} \mathrm{SiC}_{2}$ is shown in Figure 7. X-ray phase analysis showed the presence of phase $\mathrm{Ti}_{3} \mathrm{SiC}_{2}$ and $\mathrm{TiC}$ only but did not indicate the presence of impurity phases $\mathrm{TiN}$ and $\mathrm{TiO}_{2}$.

\section{Discussion}

As already mentioned in the introduction, the results of previous research on the fabrication of $\mathrm{Ti}_{3} \mathrm{SiC}_{2}$ by the SHS method show that the product of synthesis along with $\mathrm{Ti}_{3} \mathrm{SiC}_{2}$ contains the impurity phases, mainly titanium carbide (TiC), that is, the material synthesized is $\mathrm{Ti}_{3} \mathrm{SiC}_{2}$ - $\mathrm{TiC}$ composite. The percentage of $\mathrm{TiC}$ in the resulting material can range from 20 to 80 percent. This is largely explained by evaporation of silicon (Si) in the combustion process and its lack of availability for the formation of $\mathrm{Ti}_{3} \mathrm{SiC}_{2}$. To minimize the amount of titanium carbide in the product, an excess of silicon is added in the initial charge, while the recommended amount of additive is $15 \%$ by weight of silicon (Meng, et al., 2013). Thus a ratio of $\mathrm{Ti}_{3} \mathrm{SiC}_{2} / \mathrm{TiC}$ as $70 / 30 \%$ can be achieved in the resulting material. About the same result is obtained in the present work, if we are based on the composition of the charge $3 \mathrm{Ti}+1.15 \mathrm{Si}+2 \mathrm{C}$ and results of the synthesis are presented in Figures 3 and 7.

As shown by the results of the present work, the gas atmosphere during the SHS process has a significant influence on the morphology and surface structure of the porous frame of $\mathrm{Ti}_{3} \mathrm{SiC}_{2}$. On the surface of the pore space of $\mathrm{Ti}_{3} \mathrm{SiC}_{2}$ samples synthesized in air and filling of sand, a layer of film of thickness of 2-3 microns is formed (Figures 2 and 3). From the results of elemental analysis of the chemical composition, it follows that a surface film must contain oxides and nitrides (Table 1).

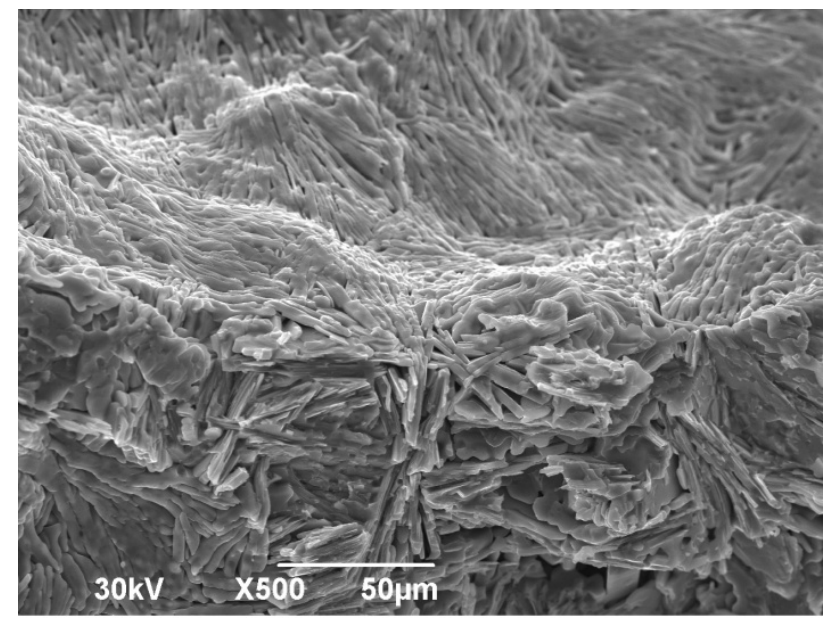

Figure 5. Microstructure of the surface of $\mathrm{Ti}_{3} \mathrm{SiC}_{2}$, synthesized in argon atmosphere

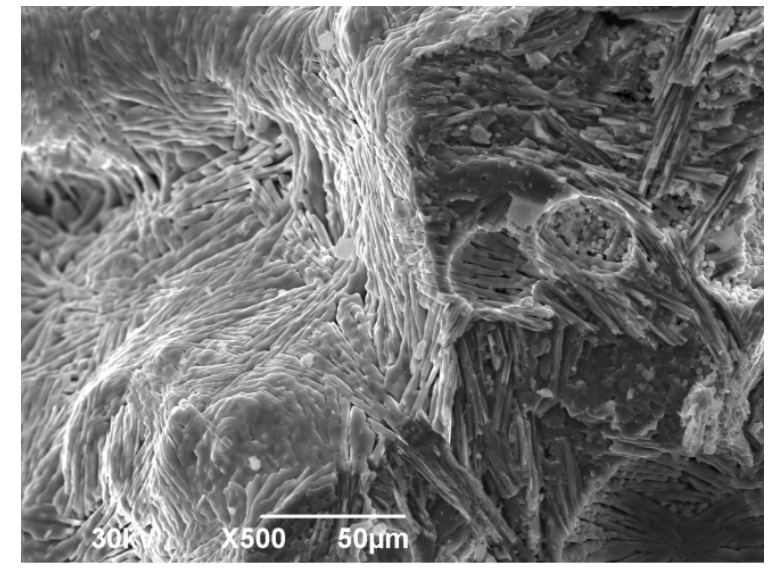

Figure 6. Microstructure of the surface of Ti3SiC2 synthesized in vacuum 
In previous work (Liang, et al., 2009) were found the formation of a film on the surface of the porous $\mathrm{Ti}_{3} \mathrm{SiC}_{2}$ obtained from mechanically activated mixture of powders $3 \mathrm{Ti}+\mathrm{Si}+2 \mathrm{C}$ through the performance of SHS process in the air. Based on the results of X-ray phase analysis, it was concluded that this oxide film consists mainly of titanium oxide $\left(\mathrm{TiO}_{2}\right)$. A scheme of self-ignition of the mechanically activated initial mixture of powders in the air and initiation of the SHS process was also proposed (Liang, et al., 2009). The self-ignition starts due to reactions between components of the activated mixture on the surface of the preform with oxygen:

$$
\mathrm{Ti}+\mathrm{O}_{2}=\mathrm{TiO}_{2} ; \quad \mathrm{C}+\mathrm{O}_{2}=\mathrm{CO}_{2} ; \quad \mathrm{Si}+\mathrm{O}_{2}=\mathrm{SiO}_{2} .
$$

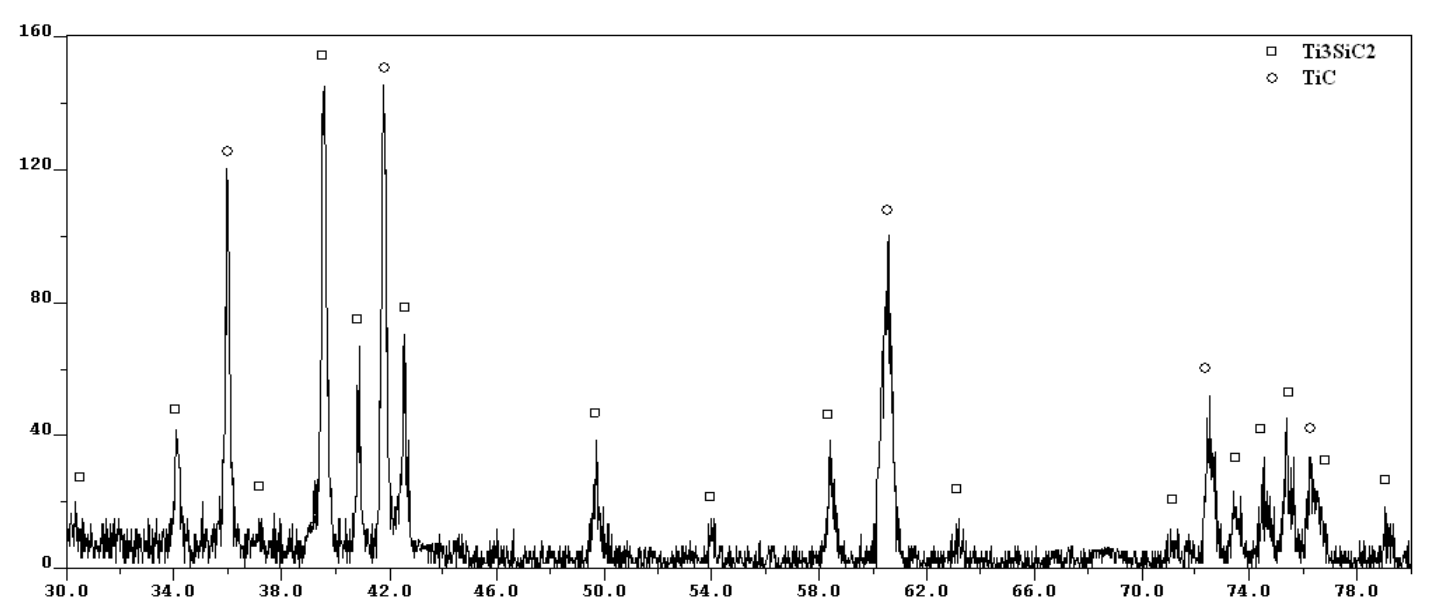

Figure 7. Typical X-ray diffraction pattern of titanium silicon carbide sample obtained by SHS

Gaseous $\mathrm{CO}_{2}$ immediately leaves the surface. The content of $\mathrm{SiO}_{2}$ in the film is considerably less than that of $\mathrm{TiO}_{2}$ due to the smaller $\mathrm{Si}$ content in the initial mixture of powders compared with the content of Ti. In addition, $\mathrm{SiO}_{2}$ is amorphous, therefore, when X-ray phase analysis is not detected. On the basis of the above, it was concluded that the surface film is an oxide film and is composed mainly of $\mathrm{TiO}_{2}$ (Liang, et al., 2009). This film prevents the diffusion of oxygen deep into the porous preform, where the SHS reactions of the formation of titanium silicon carbide and titanium carbide are initiated under the action of heat generation of the surface oxidation:

$$
3 \mathrm{Ti}+\mathrm{Si}+2 \mathrm{C}=\mathrm{Ti}_{3} \mathrm{SiC}_{2} ; \quad \mathrm{Ti}+\mathrm{C}=\mathrm{TiC} .
$$

Our results of elemental analysis presented in Table 1 allow us to coclude that on the surface of the porous $\mathrm{Ti}_{3} \mathrm{SiC}_{2}$ during the process of SHS in the air, not only oxides are formed, but nitrides also, mainly, it has to be titanium nitride (TiN). The formation of titanium nitride along with titanium oxide in the combustion of titanium powder in an atmosphere of air is a known fact (Strokova, et al., 2008). Perhaps, in the work (Liang, et al., 2009), when X-ray phase analysis was conducted, the titanium nitride was not detected because of its small quantity. In our work, we used the method of energy dispersive analysis, the results of which allow us to suggest the presence of titanium nitride $(\mathrm{TiN})$ along with titanium oxide $\left(\mathrm{TiO}_{2}\right)$ on the surface of the porous $\mathrm{Ti}_{3} \mathrm{SiC}_{2}$ obtained by the SHS method in the atmosphere of air. As the quantitative content of $\mathrm{TiN}$ and $\mathrm{TiO}_{2}$ in the $\mathrm{Ti}_{3} \mathrm{SiC}_{2}-\mathrm{TiC}$ composite is very little (they are only in a thin film on the surface, but absent in the depth of the samples), X-ray phase analysis of the burned samples does not show the presence of $\mathrm{TiN}^{2}$ and $\mathrm{TiO}_{2}$ (Figure 7). Based on the results of energy dispersive analysis (they are not represented here), we can also assume that the conglomerates of particles formed on the film (Figure 4) during the process of SHS in nitrogen atmosphere are particles of titanium nitride. The presence of titanium nitride on the surface of the porous material can have a great importance, for example, TiN significantly improves the biocompatibility of the material used in implants (Ilyushenko, et al., 2010; Browne \& Gregson, 1994; Sul \& Johansson, 2005).

Thus, by changing the composition of the gas atmosphere in obtaining the porous $\mathrm{Ti}_{3} \mathrm{SiC}_{2}$ by the SHS method, you can control the formation and composition of the film on the surface of the synthesized porous material.

\section{Conclusion}

The influence of the composition of the gas atmosphere in the performance of SHS of $\mathrm{Ti}_{3} \mathrm{SiC}_{2}$ on the structure and composition of the synthesized material have been investigated. It is shown that under these conditions, a porous composite material consisting of the main phases of $\mathrm{Ti}_{3} \mathrm{SiC}_{2}$ and $\mathrm{TiC}$ is synthesized. During the synthesis 
in the atmospheres of air and nitrogen, the film of 2-3 microns thickness consisting of oxide and nitride of titanium $\left(\mathrm{TiO}_{2}\right.$ and $\left.\mathrm{TiN}\right)$ is formed on the surface of the porous material. During the SHS process in the inert argon atmosphere and in vacuum, this film is not formed. In nitrogen atmosphere, the conglomerates of particles of titanium nitride are formed on the film as well.

Because of the small content, the $\mathrm{TiO}_{2}$ and TiN phases may not be detected with the total X-ray phase analysis of the synthesized material. To clarify the composition and structure of the surface layer formed during self-propagating high-temperature synthesis of $\mathrm{Ti}_{3} \mathrm{SiC}_{2}$ in the different gas atmospheres, it is necessary to conduct further research using more refined methods of analysis. In this case, other phases can be detected on the surface, for example, titanium oxynitride.

\section{References}

Adler, J. (2005). Ceramic diesel particulate filters. International Journal of Applied Ceramic Technology, 2(6), 429-439. http://dx.doi.org/10.1111/j.1744-7402.2005.02044.x

Barsoum, M. W. (2000). The $\mathrm{M}_{n+1} \mathrm{AX}_{n}$ phases: A new class of solids. Thermodynamically stable nanolaminates. Progress in Solid State Chemistry, 28, 201-281. http://dx.doi.org/10.1016/s0079-6786(00)00006

Browne, M., \& Gregson, P. J. (1994). Surface modification of titanium alloy implants. Biomaterials, 15(11), 894-898. http://dx.doi.org/10.1016/0142-9612(94)90113-9

Emmela, M., Anezirisa, C., Sponzab, F., Dudcziga S., \& Colombob, P. (2014). In situ spinel formation in $\mathrm{A} 12 \mathrm{O} 3-\mathrm{MgO}-\mathrm{C}$ filter materials for steel melt filtration. Ceramics International, 40(8, B), 13507-13513. http://dx.doi.org/10.1016/j.ceramint.2014.05.033

Fraczkiewicz, M., Zhou, A. G., \& Barsoum, M. W. (2006). Mechanical damping in porous $\mathrm{Ti}_{3} \mathrm{SiC}_{2}$. Acta Materialia, 54(19), 5261-5270. http://dx.doi.org/10.1016/j.actamat.2006.06.052

Hu, C., Zhang, H., Li, F., Huang, Q., \& Bao, Y. (2013). New phases' discovery in MAX family. International Journal of Refractory Metals and Hard Materials, 36, 300-312. http://dx.doi.org/10.1016/j.jirmhm.2012.10.011

Hu, L., Kothalkar, A., Proust, G., Karaman, I., \& Radovic, M. (2014). Fabrication and characterization of $\mathrm{NiTi} / \mathrm{Ti}_{3} \mathrm{SiC}_{2}$ and $\mathrm{NiTi} / \mathrm{Ti}_{2} \mathrm{AlC}$ composites. Journal of Alloys and Compounds, 610, 635-644. http://dx.doi.org/10.1016/j.jallcom.2014.04.224

Ilyushenko, A. F., \& Savich, V. V. (2010). Opportunities and prospects for the use of technologies of powder metallurgy, surface modification and deposition of protective coatings in medical appliances. In A. F. Ilyushenko, E. E. Petyushik, \& V. V. Savich (Eds.), 50 years of powder metallurgy of Belarus. History, achievements, perspectives ( pp. 541-582). Minsk. (in Russian). http://www.science.by/library/books/article/?ELEMENT_ID=133

Jeitschko, W., \& Nowotny, H. (1967). Die Kristallstructur von $\mathrm{Ti}_{3} \mathrm{SiC}_{2}$ - Ein Neuer Komplexcarbid-Tip. Monatshefte fur Chemie, 98(2), 329-337

Kašpar, J., Fornasiero, P., \& Hickey, N. (2003). Automotive catalytic converters: Current status and some perspectives. Catalysis Today, 77(4), 419-449. http://dx.doi.org/10.1016/S0920-5861(02)00384-X

Li, H., Peng, L. M., Gong, M., Zhao, J. H., He, L. H., \& Guo, C. Y. (2004). Preparation and characterization of $\begin{array}{lllll}\text { Ti3SiC2 } 2 \text { powder. } & \text { Ceramics }\end{array}$ http://dx.doi.org/10.1016/j.ceramint.2004.01.009

Liang, B. Y., Wang, M. Z., Sun, J. F., Li, X. P., Zhao, Y. C., \& Han, X. (2009). Synthesis of $\mathrm{Ti}_{3} \mathrm{SiC}_{2}$ in air using mechanically activated 3Ti/Si/2C powder. Journal of Alloys and Compounds, 47(1-2), L18-L21.

Liu, P. S., \& Chen, G. F. (2014). Porous Materials. Processing and Applications. Elsevier, 560. ISBN: 9780124077881

Meng, F., Liang, B., \& Wang, M. (2013). Investigation of formation mechanism of $\mathrm{Ti}_{3} \mathrm{SiC}_{2}$ by self-propagating high-temperature synthesis. International Journal of Refractory Metals and Hard Materials, 41, 152-161. http://dx.doi.org/10.1016/j.jirmhm.2013.03.005

Myhra, S., Summers, J. W. B., \& Kisi, E. H. (1999). $\mathrm{Ti}_{3} \mathrm{SiC}_{2}-\mathrm{A}$ layered ceramic exhibiting ultra-low friction. Materials Letters, 39(1), 6-11. http://dx.doi.org/10.1016/S0167-577X(98)00206-7

Ngai, T. L., Lu, L., Chen, J., Zhang, J., \& Li, Y. (2014). Preparation of SiC reinforced $\mathrm{Ti}_{3} \mathrm{SiC}_{2}$-base composite and its biocompatibility evaluation. Ceramics International, 40(4), 5343-5348. 
http://dx.doi.org/10.1016/j.ceramint.2013.10.113

Pampuch, R., Lis, J., Stobierski, L., \& Tymkiewicz, M. (1989). Solid combustion synthesis of $\mathrm{Ti}_{3} \mathrm{SiC}_{2}$. Journal of the European Ceramic Society, 5(5), 283-287. http://dx.doi.org/10.1016/0955-2219(89)90022-8

Ren, S., Meng, J., Lu, J., Yang, S., \& Wang, J. (2010). Tribo-physical and tribo-chemical aspects of WC-based cermet $/ \mathrm{Ti}_{3} \mathrm{SiC}_{2}$ tribo-pair at elevated temperatures. Tribology International, 43(1-2), 512-517. http://dx.doi.org/10.1016/j.triboint.2009.08.007

Shiganova, L. A., Bichurov, G. V., Amosov, A. P., Titova, Y. V., Ermoshkin, A. A., \& Bichurova, P. G. (2011). The Self-Propagating High-Temperature Synthesis of a Nanostructured Titanium Nitride Powder with the Use of Sodium Azide and Haloid Titanium Containing Salt. Russian Journal of Non_Ferrous Metals, 52(1), 91-95. http://dx.doi.org/10.3103/S1067821211010238

Smorygo, O., Mikutski, V., Leonov, A., Marukovich, A., \& Vialiuha, Y. (2008). Nickel foams with oxidation-resistant coatings formed by combustion synthesis. Scripta Materialia, 58(10), 910-913. http://dx.doi.org/10.1016/j.scriptamat.2008.01.014

Strokova, Y. I., Gromov, A. A., Ponomareva, M. Y., \& Vereshchagin, V. I. (2008). Nitride formation during combustion of $\mathrm{Ti}^{-\mathrm{TiO}_{2}}$ and Ti-Al powder mixture in air under SHS conditions. Combustion, Explosion, and Shock Waves, 44(5), 614-618. Springer: 0010-5082/08/4405-0614

Sul, Y. T., \& Johansson, C. (2005). The bone response of oxidized bioactive and non-bioactive titanium implants. Biomaterials, 26, 6720-6730. http://dx.doi.org/10.1016/j.biomaterials.2005.04.058

Sun, Z. M., Murugaiah, A., Zhen, T., Zhou, A., \& Barsoum, M. W. (2005). Microstructure and mechanical properties of porous $\mathrm{Ti}_{3} \mathrm{SiC}_{2}$. Acta Materialia, 53(16), 4359-4366. http://dx.doi.org/10.1016/j.actamat.2005.05.034

Vityaz, P. A., Kaptsevich, V. M., Kusin, R. A., Pilinevich, L. P., Rak, A. L., Smorygo, O. L., \& Sheleg, V. K. (2010). Porous powder materials: History, current status and future development. In A. F. Ilyushenko, E. E. Petyushik, V. V. Savich (Eds.), 50 years of powder metallurgy of Belarus. History, achievements, $\begin{array}{lllll}\text { perspectives (in } & \text { 251-320). } & \text { Minsk. } & \text { Russian). }\end{array}$ http://www.science.by/library/books/article/?ELEMENT_ID=123

Zhou, C. L., Ngai, T. W. L., Lu, L., \& Li, Y. Y. (2014). Fabrication and characterization of pure porous Ti3SiC2 with controlled porosity and pore features. Materials Letters, 131, 280-283. http://dx.doi.org/10.1016/j.matlet.2014.05.198

\section{Copyrights}

Copyright for this article is retained by the author(s), with first publication rights granted to the journal.

This is an open-access article distributed under the terms and conditions of the Creative Commons Attribution license (http://creativecommons.org/licenses/by/3.0/). 